\title{
Composição bromatológica de silagens de milho produzidas com diferentes densidades de compactação ${ }^{1}$
}

\section{João Pedro Velho², Paulo Roberto Frenzel Mühlbach ${ }^{3}$, José Laerte Nörnberg ${ }^{4}$, Ione Maria Pereira Haygert Velho ${ }^{5}$, Teresa Cristina Moraes Genro ${ }^{6}$, Julcemar Dias Kessler ${ }^{7}$}

\author{
${ }_{1}$ Projeto parcialmente financiado pelo CNPq, com recursos da bolsa prêmio do segundo autor. \\ 2 Doutorando - UFRGS. Bolsista CNPq. \\ 3 Departamento de Zootecnia - UFRGS. \\ ${ }^{4}$ Departamento de Tecnologia e Ciência de Alimentos - UFSM. \\ ${ }^{5}$ Doutoranda - UFRGS. Bolsista CAPES. \\ ${ }^{6}$ EMBRAPA Pecuária Sul. \\ ${ }^{7}$ Mestrando - UFPel. Bolsista CNPq.
}

RESUMO - O experimento foi conduzido em delineamento completamente casualizado com o objetivo de avaliar o efeito da densidade de compactação, $500 \mathrm{~kg}$ (médio) e $600 \mathrm{~kg}$ (alto) de matéria verde por metro cúbico de massa ensilada, na qualidade final da silagem em relação ao material original. A ensilagem de milho safrinha foi realizada no dia 18/05/2004 em minissilos, com quatro repetições por grau de compactação, quando os grãos de milho se encontravam no estádio $1 \frac{1}{2}$ leitoso $1 \frac{1}{2}$ farináceo. As densidades de compactação afetaram significativamente os teores de açúcares solúveis $(1,60 \times 2,15 \%$ da MS $)$, matéria orgânica do resíduo insolúvel em etanol a $80 \%(76,02 \times 71,53 \%$ da MS), carboidratos não-estruturais $(39,21 \times 41,70 \%$ dos carboidratos totais), fibra em detergente neutro corrigida para cinzas e proteína $(52,57 \times 50,37 \%$ da MS), lignina em detergente ácido $(2,74 \times 2,57 \%$ da MS) e nitrogênio amoniacal $(4,35 \times 3,84 \%$ do nitrogênio total). A maior densidade de compactação resultou em melhor conservação dos glicídios solúveis, em menor alteração dos carboidratos estruturais e em menor proteólise na silagem de milho.

Palavras-chave: amido, carboidrato, estádio de maturação, FDN, proteína, NDT

\section{Chemical composition of maize silages with different packing densities}

ABSTRACT - The experiment in a complete randomized design aimed to test the effect of two packing densities, $500 \mathrm{~kg}$ (medium) and $600 \mathrm{~kg}$ (high) of silage mass per cubic meter, on silage quality as compared to the original fresh material Silages were prepared on May $18^{\text {th }}, 2004$ from a late season harvest of a maize crop at the half milky half dough kernel stage. Chopped materials with $1.2 \mathrm{~cm}$ theoretical particle size were packed manually in 30 liters mini-silos, in four replicates for each packing density, immediately after harvest. The different packing densities affected significantly the concentration of soluble sugars (1.60 vs. $2.15 \%$ of DM), $80 \%$ ethanol insoluble organic matter (76.02 vs. $71.53 \%$ of DM), non-structural carbohydrates (39.21 vs. $41.70 \%$ of total carbohydrates), neutral detergent fiber corrected for ash and protein (52.57 vs. $50.37 \%$ of DM), acid detergent lignin (2.74 vs. $2.57 \%$ of DM), and ammonia-nitrogen (4.35 vs. $3.84 \%$ of total nitrogen), respectively, for the "medium" and "high" packing densities. A higher ensiling packing density improved the conservation of soluble sugars, altered less the structural carbohydrates and reduced proteolysis in maize silage.

Key Words: carbohydrate, maturity stage, NDF, protein, starch, TDN

\section{Introdução}

O grande desafio na alimentação de ruminantes de alta produtividade é aumentar sua capacidade de ingestão de alimento para suprir suas necessidades nutricionais sem prejudicar os processos fisiológicos no rúmen, ou seja, mantendo a atividade de ruminação com consumo adequado de volumoso. A planta de milho inteira, verde ou na forma de silagem, permite maior consumo em razão do seu teor relativamente baixo de FDN (menos de 50\%), pois quanto menor o teor de FDN maior a taxa de fermentação da FDN, ou seja, ocorre esvaziamento mais rápido do rúmen.

A silagem de milho fornece 50 a $100 \%$ a mais de energia digestível por hectare que qualquer outra forrageira. Entretanto, o valor nutritivo da silagem de milho pode variar conforme o híbrido, a densidade de cultivo, as condições de crescimento, a maturidade e a umidade no 
momento da colheita, o tamanho de partícula e as condições de ensilagem (Satter \& Reis, 2005) e desensilagem (Velho et al., 2006).

Para produzir silagem de boa qualidade, a forrageira deve ser picada e compactada e o silo deve ser fechado no menor espaço de tempo possível, mantendo-se as condições anaeróbias a fim de que as características qualitativas da silagem sejam similares à da forragem verde (Senger et al., 2005). A correta compactação da silagem é importante para excluir o oxigênio e garantir condições anaeróbias para preservação dos nutrientes (Johnson et al., 2002). A densidade e o teor de matéria seca determinam a porosidade da silagem, a qual estabelece a taxa de aeração da silagem e, posteriormente, o grau de deterioração na armazenagem e na desensilagem (Bolsen \& Bolsen, 2004).

Avaliando graus de compactação de 130 a $195 \mathrm{~kg}$ de $\mathrm{MS} / \mathrm{m}^{3}$ em minissilos, Johnson et al. (2002) observaram alta recuperação do material original. Esses autores avaliaram a influência dos fatores híbrido, maturidade, método de processamento, tamanho de partícula e ano na densidade de compactação e verificaram que o fator que mais afetou a compactação da silagem foi o método de ensilagem, seguido pelas interações método de processamento $\times$ maturidade.

No entanto, Savoie et al. (2004), em experimento com minissilos, avaliaram quatro pressões de compactação na ensilagem de milho fazendo o controle número de camadas (seis), a espessura $(30 \mathrm{~cm})$ e o peso $(22,7 \mathrm{~kg})$ da camada a ser compactada e o tempo de compactação (cinco segundos) obtiveram 169, 240, 233 e $261 \mathrm{~kg}$ de $\mathrm{MS} / \mathrm{m}^{3}$ para as pressões de compactação de 20, 40, 60 e $80 \mathrm{kPa}$. Esses autores comprovaram que a densidade final não é linear, pois a compactação é função logarítmica do número de camadas compactadas.

Quanto maior a densidade maior a capacidade do silo. Logo, densidades maiores reduzem o custo anual de armazenamento por tonelada de silagem e as perdas durante a armazenagem (Bolsen \& Bolsen, 2004). Os fatores que afetam a densidade de compactação são peso do trator, tempo de compactação, teor de água das plantas, altura do silo e tamanho das partículas (Muck \& Holmes, 2000). Por outro lado, é possível obter silagem de baixa qualidade com uma forrageira de alta qualidade se a tecnologia empregada não for adequada (Jobim et al., 2005).

No Brasil, provavelmente, os dois fatores que mais influenciam a densidade de compactação das silagens de milho são a maturidade da planta e o tamanho de partícula, pois as ensiladeiras nacionais geralmente não são equipadas para realização do processo de esmagamento da planta após a picagem, como ocorre na América do Norte e na Europa. Esse tipo de processamento, além de aumentar a densidade de compactação, segundo Johnson et al. (2003), melhora a digestibilidade da FDN.

Neste estudo, objetivou-se avaliar o efeito da densidade de compactação sobre a qualidade da silagem de milho.

\section{Material e Métodos}

O trabalho de campo foi desenvolvido em uma propriedade particular no município de Palmeira das Missões, RS. O solo é classificado como latossolo vermelho distrófico típico LVd3 (Streck et al., 2002) e o clima é do tipo Cfa, subtropical, com verões quentes e chuvas bem distribuídas ao longo do ano, com temperatura média de $22^{\circ} \mathrm{C}$ no período mais quente (Moreno, 1961).

O híbrido triplo AG5011, de ciclo precoce, com grão dentado de cor amarela, foi semeado em janeiro de 2004, em sistema de plantio direto com espaçamento entre linhas de $0,75 \mathrm{~m}$ e com estande final de $50.000 \mathrm{plantas} / \mathrm{h}$. A adubação de plantio foi feita com NPK, $250 \mathrm{~kg} /$ ha da fórmula $08-18-28$, e a adubação de cobertura, com uréia na quantidade de $100 \mathrm{~kg} / \mathrm{ha}$, divididos em duas aplicações.

A colheita foi realizada manualmente no período de 16 às $18 \mathrm{~h}$, desprezando-se as bordaduras $(5 \mathrm{~m})$ e cortando as plantas a $15 \mathrm{~cm}$ do nível do solo, quando os grãos se encontravam no estádio de maturidade $1 / 2$ leitoso $1 / 2$ farináceo, no dia 18 de maio de 2004. Foram colhidos aproximadamente $1.000 \mathrm{~kg}$ de matéria verde e, em seguida, procedeu-se à picagem das plantas em ensiladeira regulada para tamanho de partícula médio de $1,2 \mathrm{~cm}$. Imediatamente, efetuaram-se o enchimento, a compactação e o fechamento manual dos minissilos em baldes de $30 \mathrm{~L}$ de capacidade, de modo que diferissem apenas quanto à densidade de compactação desejada, de 500 (média) ou de 600 (alta) kg de matéria verde por metro cúbico. No momento da abertura dos minissilos, realizada 45 dias após o fechamento, as camadas superiores, inferiores e laterais de cada minissilo foram desprezadas.

Imediatamente após a desensilagem, procedeu-se à determinação do teor de matéria parcialmente seca em parte do material e o restante foi armazenado a $-18^{\circ} \mathrm{C}$.

Para determinação do $\mathrm{pH}$ e do nitrogênio amoniacal, coletaram-se $50 \mathrm{~mL}$ de extrato por meio de prensagem. $\mathrm{OpH}$ foi determinado no extrato utilizando-se potenciômetro digital, enquanto o teor de nitrogênio amoniacal foi obtido pelo método colorimétrico, segundo Weatherburn (1967).

A determinação dos teores de MS, MO, EE, FDA, lignina em detergente ácido (LDA), PB, nitrogênio insolúvel 
em detergente neutro (NIDN) e nitrogênio insolúvel em detergente ácido (NIDA) foi realizada segundo procedimentos descritos por Silva \& Queiroz (2002). Ressalta-se que na determinação da FDN não foi utilizado sulfito de sódio na solução detergente, porém utilizou-se alfa-amilase.

Por isso, a proteína remanescente na FDN foi subtraída após multiplicação do fator 6,25 pelo teor do NIDN. A abreviação FDNcp representa o teor de FDN determinado com o uso de $\alpha$-amilase termoestável descontando-se a proteína insolúvel em detergente neutro (PIDN) e as cinzas residuais.

Os teores de açúcares solúveis (AS) e de matéria orgânica do resíduo insolúvel em etanol a $80 \%$ (MORIE) foram determinados conforme Hall (2000). A determinação do teor de amido foi realizada de acordo com a metodologia descrita por Walter et al. (2005). Foram feitos os cálculos do fracionamento dos carboidratos segundo o CNCPS v5.0: fração A (açúcares solúveis) - de rápida degradação; fração B1 (amido) - de média degradação; fração B2 (parede celular disponível) - de lenta degradação; e fração C (parede celular indigestível) - indegradável pelas fórmulas de Sniffen et al. (1992).

Os valores de nutrientes digestíveis totais (NDT) foram estimados segundo Weiss et al. (1992) e NRC (2001), respectivamente, utilizando-se as equações:

$$
\begin{aligned}
\mathrm{NDT}_{1 \mathrm{x}}(\mathrm{g} / \mathrm{kg} \text { de MS })= & \mathrm{CNFvd}+\mathrm{PBvd}+(\mathrm{EE}-10) \times 2,25+ \\
& \text { FDNvd }-70
\end{aligned}
$$

$\mathrm{NDT}_{1 \mathrm{x}}(\%)=\mathrm{CNFvd}+\mathrm{PBvd}+(\mathrm{EE}-1) \times 2,25+\mathrm{FDNvd}-7$ em que: NDT1 $x=$ nutrientes digestíveis totais para o consumo de $1 \mathrm{x}$ a mantença; $\mathrm{CNFvd}$ = carboidratos não-fibrosos verdadeiramente digestíveis; $\mathrm{PBvd}=$ proteína bruta verdadeiramente digestível; FDNvd = fibra em detergente neutro verdadeiramente digestível; e 70 ou $7=$ constante de desconto de constituintes metabólicos fecais.

O delineamento experimental foi o completamente casualizado, com quatro repetições (minissilos). As análises estatísticas foram realizadas pelo modelo estatístico:

$$
\mathrm{Y}_{\mathrm{ij}}=\mu+\alpha_{\mathrm{i}}+\varepsilon_{\mathrm{ij}}
$$

em que: $Y_{i j}=$ variável-resposta; $\mu=$ média geral; $\alpha_{i}=$ efeito dos diferentes graus de compactação da ensilagem, $i=500$ ou $600 \mathrm{~kg}$ de matéria verde por metro cúbico; $\varepsilon_{\mathrm{ij}}=$ erro aleatório. O material original não foi incluído na análise estatística. Empregou-se o software SPSS (2002) para comparação entre os tratamentos utilizando-se teste $t$ de Student a $5 \%$ para amostras independentes.

\section{Resultados e Discussão}

A diferença de $32,6 \mathrm{~kg}$ de $\mathrm{MS} / \mathrm{m}^{3}$ obtida entre os dois graus de compactação não foi suficiente para gerar diferenças significativas nos teores de MS, MO, EE e nos valores de pH no nível de 5\% (Tabela 1). Entretanto, considerando $\mathrm{P}<0,074$, houve diferença significativa no teor de MS, ou seja, o menor grau de compactação ( $500 \mathrm{~kg}$ de $\mathrm{MV} / \mathrm{m}^{3}$ ) ocasionou perdas de aproximadamente 0,8 unidade percentual no teor de MS.

Os teores de EE (Tabela 1) obtidos com o maior grau de compactação foram semelhantes aos encontrados por Campos et al. (2000), de 2,2\% da MS em silagens de milho com 29,3\% de MS. No entanto, a determinação do teor de EE teve como objetivo utilizá-lo no cálculo dos nutrientes digestíveis totais.

$\mathrm{O}$ valor de $\mathrm{pH}$ do material original $(5,62)$ foi inferior aos obtidos por Muck (2004), de 5,90; 5,98 e 5,79, respectivamente, para plantas de milho colhidas em 1999, 2000 e 2001, e superior ao obtido por Ranjit \& Kung Jr. (2000), de 5,44, para plantas de milho colhidas com $31,3 \%$ de MS. Os valores de $\mathrm{pH}$ das silagens produzidas foram semelhantes aos encontrado por Muck (2004) em silagem de milho $(3,82)$ produzida sem inoculante e com densidade de compactação de $173 \mathrm{~kg}$ de $\mathrm{MS} / \mathrm{m}^{3}$.

Houve efeito $(\mathrm{P}<0,05)$ do grau de compactação das silagens sobre os teores de AS, MORIE e carboidratos nãoestruturais (CNE) (Tabela 2). Entretanto, não foi constatado efeito sobre os teores de amido e carboidratos totais (CT).

Di Marco et al. (2002) avaliaram silagem de milho produzida com grão no estádio $1 / 2$ leitoso $1 / 2$ farináceo, $32 \%$ de MS e com densidade de compactação de $179 \mathrm{~kg}$ de $\mathrm{MS} / \mathrm{m}^{3}$ na região da Província de Buenos Aires, Argentina, e

Tabela 1 - Quantidade de matéria verde e seca $\left(\mathrm{kg} / \mathrm{m}^{3}\right)$, teores médios de MS, MO, EE e valores de $\mathrm{pH}$ do materia original e das silagens

Table 1 - Packing densities $\left(\mathrm{kg} / \mathrm{m}^{3}\right)$ expressed in fresh matter and DM,

\begin{tabular}{|c|c|c|c|c|}
\hline \multirow[t]{2}{*}{$\begin{array}{l}\text { Variável } \\
\text { Variable }\end{array}$} & \multirow[t]{2}{*}{$\begin{array}{c}\text { Material } \\
\text { original } \\
\text { Original material }\end{array}$} & \multicolumn{2}{|c|}{$\begin{array}{l}\text { Densidade de } \\
\text { compactação } \\
\text { Packing density }\end{array}$} & \multirow[t]{2}{*}{$\mathrm{P}>$} \\
\hline & & $\begin{array}{l}\text { Média } \\
\text { Medium }\end{array}$ & $\begin{array}{r}\text { Alta } \\
\text { High }\end{array}$ & \\
\hline $\begin{array}{l}\mathrm{kg} \text { de } \mathrm{MV} / \mathrm{m}^{3} \\
\mathrm{~kg} \text { fresh } \text { matter } / \mathrm{m}^{3}\end{array}$ & $m^{3}$ & 491,5 & 591,3 & - \\
\hline $\begin{array}{l}\mathrm{kg} \text { de } \mathrm{MS} / \mathrm{m}^{3} \\
\mathrm{~kg} D M / \mathrm{m}^{3}\end{array}$ & - & 137,2 & 169,8 & - \\
\hline $\begin{array}{l}\text { MS (\%) } \\
D M(\%)\end{array}$ & 30,83 & 27,91 & 28,71 & 0,074 \\
\hline $\begin{array}{l}\text { MO (\% MS) } \\
O M(\% D M)\end{array}$ & 97,46 & 96,41 & 95,97 & 0,126 \\
\hline $\begin{array}{l}\mathrm{EE}(\% \mathrm{MS}) \\
E E(\% \mathrm{DM})\end{array}$ & 2,20 & 2,48 & 2,28 & 0,219 \\
\hline $\mathrm{pH}$ & 5,62 & 3,77 & 3,72 & 0,127 \\
\hline
\end{tabular}
and concentration of $O M, E E$, and $p H$ of the silages and original material

* Os dados do material original não fazem parte da análise estatística.

* Original material values are not analyzed statistically. 
Tabela 2 - Teores médios de açúcares solúveis (AS), amido, matéria orgânica do resíduo insolúvel em etanol a 80\% (MORIE), carboidratos não-estruturais (CNE) e carboidratos totais (CT) do material original e das silagens

Table 2 - Average concentration of total $80 \%$ ethanol soluble carbohydrates (TESC), starch, ethanol insoluble residue organic matter (EIROM), non-structural carbohydrates (NSC), and total carbohydrates (TC) of the original material and silages

\begin{tabular}{|c|c|c|c|c|}
\hline \multirow[t]{2}{*}{ Orig } & \multirow[t]{2}{*}{$\begin{array}{l}\text { Material } \\
\text { original } \\
\text { iginal material }\end{array}$} & \multicolumn{2}{|c|}{$\begin{array}{l}\text { Densidade de } \\
\text { compactação } \\
\text { Packing density }\end{array}$} & \multirow[t]{2}{*}{$\mathrm{P}>$} \\
\hline & & $\begin{array}{l}\text { Média } \\
\text { Medium }\end{array}$ & $\begin{array}{l}\text { Alta } \\
\text { High }\end{array}$ & \\
\hline $\begin{array}{l}\text { AS }(\% \mathrm{MS}) \\
\text { TESC }(\% \quad D M)\end{array}$ & 9,37 & 1,60 & 2,15 & 0,039 \\
\hline $\begin{array}{l}\text { Amido (\% MS) } \\
\text { Starch (\% DM) }\end{array}$ & 11,70 & 14,31 & 12,48 & 0,210 \\
\hline $\begin{array}{l}\text { MORIE (\% MS) } \\
\text { EIROM (\% DM) }\end{array}$ & 73,94 & 76,02 & 71,53 & 0,001 \\
\hline $\begin{array}{l}\text { CNE }(\% \mathrm{CT}) \\
\text { NSC }(\% \text { TC) }\end{array}$ & 43,01 & 39,21 & 41,70 & 0,024 \\
\hline $\begin{array}{l}\text { CT (\% MS) } \\
\text { TC (\% DM) }\end{array}$ & 87,74 & 85,92 & 85,69 & 0,687 \\
\hline
\end{tabular}

* Os dados do material original não fazem parte da análise estatística.

* Original material values are not analyzed statistically.

obtiveram $28 \%$ de amido. Esses autores atribuíram esse resultado ao adequado manejo cultural associado à irrigação com $80 \mathrm{~mm}$ de água durante a floração para evitar possível déficit hídrico. Neste estudo, os baixos teores de amido possivelmente foram conseqüência do cultivo extemporâneo do milho safrinha. Os valores de CT foram próximos aos obtidos por Backes et al. (2000) em silagens de milho de planta inteira sem $(87,25 \%)$ e com inoculante $(89,11 \%)$.

A determinação da MORIE é uma técnica de baixo custo e de fácil realização. Soluções de etanol aquoso têm sido usadas para extrair açúcares simples, oligossacarídeos e outras substâncias de baixo peso molecular de amostras de alimentos preparadas para análise de carboidratos (Hall et al., 1997). O aumento dessa fração, pela menor compactação da silagem, indica degradação de glicídios, que, posteriormente, no rúmen, fazem falta como fonte de energia na síntese de proteína microbiana.

As diferentes densidades de compactação influenciaram $(\mathrm{P}<0,011)$ o teor de FDNcp ocasionando aumentos de 0,9 unidade percentual na silagem de compactação alta em relação ao material original e 3,1 na silagem de compactação média, originada possivelmente pelo maior tempo de aerobiose causado pela menor compactação. A melhor compactação pode ter favorecido a fermentação mais homolática, ou seja, com menor desperdício de carboidratos solúveis para produção de ácido láctico (Tabela $2-\mathrm{P}<0,039$;
Tabela $4-\mathrm{P}<0,001)$, e a conseqüente redução no valor de $\mathrm{pH}$, necessário para conservação e estabilização do processo, confirmada pelos menores valores numéricos do $\mathrm{pH}$ da silagem de maior compactação (Tabela 1). Quando a anaerobiose inicial não é total, causada por compactação ineficiente, o ar residual na massa promove consumo e

Tabela 3 - Teores médios das frações da parede celular do material original e das silagens

Table 3 - Average cell wall fractions of original material and silages

\begin{tabular}{|c|c|c|c|c|}
\hline \multirow[t]{2}{*}{ Or } & \multirow[t]{2}{*}{$\begin{array}{l}\text { Material } \\
\text { original } \\
\text { iginal material }\end{array}$} & \multicolumn{2}{|c|}{$\begin{array}{l}\text { Densidade de } \\
\text { compactação } \\
\text { Packing density }\end{array}$} & \multirow[t]{2}{*}{$\mathrm{P}>$} \\
\hline & & $\begin{array}{l}\text { Média } \\
\text { Medium }\end{array}$ & $\begin{array}{l}\text { Alta } \\
\text { High }\end{array}$ & \\
\hline $\begin{array}{l}\text { FDN (\% MS) } \\
N D F(\% D M)\end{array}$ & 51,95 & 53,50 & 51,47 & 0,018 \\
\hline $\begin{array}{l}\text { FDNcp (\%MS) } \\
\text { NDFap (\% DM) }\end{array}$ & 49,45 & 52,57 & 50,37 & 0,011 \\
\hline $\begin{array}{l}\text { FDA (\% MS) } \\
A D F(\% D M)\end{array}$ & 26,06 & 28,49 & 27,52 & 0,098 \\
\hline $\begin{array}{l}\text { LDA (\% MS) } \\
A D L(\% D M)\end{array}$ & 2,44 & 2,74 & 2,57 & 0,003 \\
\hline $\begin{array}{l}\text { HEM (\% MS) } \\
\text { HEM (\%DM) }\end{array}$ & 25,89 & 25,01 & 23,95 & 0,015 \\
\hline $\begin{array}{l}\text { CEL (\% MS) } \\
\text { CEL (\%DM) }\end{array}$ & 23,62 & 25,73 & 24,98 & 0,159 \\
\hline
\end{tabular}

* Os dados do material original não fazem parte da análise estatística. FDN = fibra em detergente neutro; FDNcp = fibra em detergente neutro corrigida para cinzas e proteína; FDA = fibra em detergente ácido; LDA = lignina em detergente ácido, HEM = hemicelulose; CEL = celulose. * Original material values are not analyzed statistically.

$N D F=$ neutral detergent fiber; NDFap = neutral detergent fiber corrected for ashes and protein; $A D F=$ acid detergent fiber; $\mathrm{Hem}=$ hemicellulose; $\mathrm{Cel}=$ cellulose.

Tabela 4 - Fracionamento dos carboidratos segundo CNCPS v.5.0 do material original e das silagens

Table 4 - Carbohydrate fractioning of the original material and silages, according to the CNCPS version 5.0

\begin{tabular}{|c|c|c|c|c|}
\hline \multirow[t]{2}{*}{ Item } & \multirow[t]{2}{*}{$\begin{array}{c}\text { Material } \\
\text { original } \\
\text { Original material }\end{array}$} & \multicolumn{2}{|c|}{$\begin{array}{l}\text { Densidade de } \\
\text { compactação } \\
\text { Packing density }\end{array}$} & \multirow[t]{2}{*}{$\mathrm{P}>$} \\
\hline & & $\begin{array}{l}\text { Média } \\
\text { Medium }\end{array}$ & $\begin{array}{c}\text { Alta } \\
\text { High }\end{array}$ & \\
\hline $\begin{array}{l}\text { Fração A } \\
(\% \text { dos CT) } \\
\text { Fraction A (\% }\end{array}$ & 31,31 & 24,90 & 29,22 & 0,001 \\
\hline $\begin{array}{l}\text { Fração } \mathrm{B} 1 \\
(\% \text { dos } \\
\text { Fraction }\end{array}$ & 11,70 & 14,31 & 12,48 & 0,210 \\
\hline $\begin{array}{l}\text { Fração } \mathrm{B} 2 \\
(\% \text { dos } \\
\text { CT) }) \\
\text { Fraction } B 2(\%\end{array}$ & 50,35 & 53,15 & 51,21 & 0,036 \\
\hline $\begin{array}{l}\text { Fração C } \\
(\% \text { dos CT) } \\
\text { Fraction C }(\%\end{array}$ & TC) & 7,64 & 7,09 & 0,013 \\
\hline
\end{tabular}

* Os dados do material original não fazem parte da análise estatística. $\mathrm{CT}=$ carboidratos totais.

* Original material values are not analyzed statistically.

TC $=$ total carbohydrates. 
desperdício de carboidratos solúveis causado por respiração celular da forragem e/ou degradação por microrganismos aeróbios.

O teor de 49,45\% FDNcp (Tabela 3) do material original pode ser considerado de qualidade média em dietas para ruminantes de alta produção se comparado ao de $38,5 \%$, relatado por Mulligan et al. (2002), e ao de 41,3\%, reportado por Qiu et al. (2003). No entanto, quando comparado aos descritos por Valadares Filho et al. (2002), de 55,68\% de FDN na MS, verifica-se que o milho safrinha utilizado neste experimento apresentou valor aceitável, mesmo descontadas as cinzas e a proteína eventualmente contidas nos valores de FDN descritos por esses autores.

O teor de FDNcp (Tabela 3) do material original foi inferior ao apresentado por Tedeschi et al. (2002), de 53,2\% de FDN, para silagem de milho brasileira.

As diferenças numéricas entre os teores de FDN e FDNcp são oriundas da subtração das cinzas e PIDN na FDNcp, cujas amplitudes indicam a importância destas correções para classificação das silagens quanto à qualidade. No entanto, a maior parte da bibliografia nacional sobre silagem de milho não indica a forma como foi expresso o teor de FDN, o que dificulta avaliar se a silagem é de boa ou de média qualidade, uma que esta variação pode chegar a cinco ou seis unidades percentuais (Velho et al., 2006). Além disso, alterações na técnica de determinação da fibra insolúvel em detergente neutro freqüentemente determinam valores biológicos distorcidos, dentro e entre laboratórios. Utilizando cana-de-açúcar, capim-braquiária, silagem de milho, polpa de citros e fezes de bovino para comparar adaptações na técnica de determinação da FDN e FDA, Berchielli et al. (2001) não encontraram diferenças significativas entre os testes. Entretanto, houve amplitude de 6,44 unidades percentuais entre o sistema convencional (47,35\% da MS) de determinação da FDN e (53,79\% da MS) para a adaptação, o que gerou valores mais altos para silagem de milho. Para os demais alimentos e as fezes, a amplitude foi menor. Portanto, em sistema de produção intensivo em que a silagem de milho é o único ou principal volumoso, variação desta magnitude na FDN pode prejudicar o balanceamento da relação FDN:CNF e conduzir a alterações indesejáveis no ambiente ruminal.

A maior concentração de hemicelulose na silagem de compactação média, por si só, (Tabela 3) pode levar a inferência equivocada, uma vez que esta porção foi maior em virtude da maior queima dos carboidratos solúveis. O teor de lignina $(\mathrm{P}<0,003)$ foi afetado pelos diferentes graus de compactação. Apesar desse aumento, os valores mantiveram-se abaixo dos observados por Cabral et al. (2000), de 4,37\% da MS, Campos et al. (2001), de 3,6\% da MS para silagem com 29,6\% de MS, e Londoño Hernández et al. (2002), de 5,35 e 5,29\% da MS, respectivamente, para silagem com e sem inoculante.

Para o fracionamento dos carboidratos (Tabela 4), a diferença $(\mathrm{P}<0,05)$ na fração $\mathrm{A}$ indica a importância do uso de compactações mais adequadas, pois esta fração do alimento é de rápida degradação e sua baixa concentração na silagem pode, posteriormente, prejudicar a fermentação ruminal. Quanto maior a concentração inicial da fração A dos carboidratos melhor a conservação do material. Comparando densidades de compactação de 98 e $174 \mathrm{~kg}$ de $\mathrm{MS} / \mathrm{m}^{3}$ com $28 \%$ de MS na silagem, Senger et al. (2005) obtiveram diferenças de 4,7 unidades percentuais para a fração A dos carboidratos de silagens de milho cujo material original apresentava $11,2 \%$ dos carboidratos totais nesta fração. Neste trabalho, com a diferença menor entre as densidades de compactação, a magnitude de variação foi de 4,22 unidades percentuais, embora o material original apresentasse $31,31 \%$ dos carboidratos na fração A. Provavelmente, não houve diferença entre as silagens quanto à fração $\mathrm{B} 1$ em decorrência da não-degradação do amido pelos lactobacilos durante o processo fermentativo. Todavia, nas frações B2 e C, houve diferença $(\mathrm{P}<0,05)$, possivelmente em razão da estreita relação entre diminuição de carboidratos solúveis e um respectivo aumento proporcional nos carboidratos estruturais. O aumento nestas frações em relação ao material original pode aumentar os custos de produção em virtude das maiores proporções de concentrado a serem adicionadas à dieta com silagem de menor densidade de compactação.

As silagens de milho deste trabalho, caso fossem fornecidas como alimento único a animais em mantença, não necessitariam, pelo menos teoricamente, de correções para os teores de PB, que estão acima do valor mínimo de 7\%, aceito como limitante do crescimento microbiano para manter a fermentação ruminal.

Silagens com fermentação adequada apresentam valores de $\mathrm{pH}$ de 3,8 a 4,2, teor de ácido lático de 6,0 a 8,0\% da MS, ácido acético menor que 2, $0 \%$ da MS, ácido propiônico de 0 a $1,0 \%$ da MS, ácido butírico menor que $0,1 \%$ da MS e $\mathrm{N}-\mathrm{NH}_{3}$ inferior a $10 \%$ do nitrogênio total (Ferreira, 2001).

Os teores de $\mathrm{N}-\mathrm{NH}_{3}$ em relação ao $\mathrm{N}$ total (Tabela 5) são considerados baixos e indicam que, sob este aspecto, a fermentação foi adequada e esses valores foram menores que os obtidos por Senger et al. (2005) em silagens bem compactadas com $28 \%$ de MS (7,4\% do NT). O N-NH 3 de silagem é um real indicador da magnitude da atividade proteolítica dos clostrídios, uma vez que é produzido em pequenas quantidades por outros microrganismos da silagem e das enzimas da planta (Jobim et al., 2005). Apesar da adequada fermentação da silagem, houve efeito signifi- 
Tabela 5 - Teores médios dos constituintes nitrogenados do material original e das silagens

Table 5 - Mean values of nitrogenous fractions of the original material and silages

\begin{tabular}{|c|c|c|c|c|}
\hline \multirow[t]{2}{*}{ Item } & \multirow[t]{2}{*}{$\begin{array}{l}\text { Material } \\
\text { original } \\
\text { iginal material }\end{array}$} & \multicolumn{2}{|c|}{$\begin{array}{l}\text { Densidade de } \\
\text { compactação } \\
\text { Packing density }\end{array}$} & \multirow[t]{2}{*}{$\mathrm{P}>$} \\
\hline & & $\begin{array}{l}\text { Média } \\
\text { Medium }\end{array}$ & $\begin{array}{l}\text { Alta } \\
\text { High }\end{array}$ & \\
\hline $\begin{array}{l}\mathrm{PB}(\% \mathrm{MS}) \\
C P(\% \mathrm{DM})\end{array}$ & 7,52 & 8,01 & 8,00 & 0,980 \\
\hline $\begin{array}{l}\mathrm{N}-\mathrm{NH}_{3}\left(\begin{array}{ll}\% & \mathrm{NT}\end{array}\right) \\
\mathrm{NH}_{3}-\mathrm{N}(\% \quad \mathrm{TN})\end{array}$ & 2,28 & 4,35 & 3,84 & 0,014 \\
\hline $\begin{array}{l}\text { NIDN (\% PB) } \\
\text { NDIN (\% CP) }\end{array}$ & 24,48 & 14,40 & 17,02 & 0,426 \\
\hline $\begin{array}{l}\text { NIDA (\%PB) } \\
A D I N(\% \quad C P)\end{array}$ & 9,10 & 12,91 & 13,49 & 0,830 \\
\hline
\end{tabular}

* Os dados do material original não fazem parte da análise estatística.

* Original material values are not analyzed statistically.

cativo $(\mathrm{P}<0,05)$ do grau de compactação das silagens em relação aos teores de $\mathrm{N}-\mathrm{NH}_{3}$, indicando que pequenas diferenças de compactação ocasionam mudanças consideráveis na qualidade da silagem em parâmetros que podem interferir na aceitabilidade e no consumo animal. Segundo DLG (2001), citado por Mühlbach (2003), além da qualidade bromatológica, todos os aspectos possíveis de afetar a palatabilidade das silagens, como qualidade fermentativa (teor de ácido butírico e produtos da degradação protéica, como amônia e aminas), características higiênicas e alterações decorrentes do manejo de silagens, são de fundamental importância para maximização do potencial de consumo de vacas de alta produção de leite.

Os teores de NIDN e NIDA das silagens não diferiram estatisticamente (Tabela 5); apenas modificaram-se inversamente em relação ao material original, de modo que o aumento dos teores de NIDA contribuiu para incrementar a porção indigestível do nitrogênio.

As diferenças numéricas (Tabela 6) para NDT1x entre os valores obtidos pelas fórmulas de Weiss et al. (1992) e NRC (2001) decorreram de duas diferenças nas equações: a primeira é que Weiss et al. (1992) consideraram que a proteína insolúvel em detergente ácido apresenta digestibilidade de $30 \%$, a qual é adicionada ao cálculo da FDNvd; e a segunda é que o NRC (2001) propõe um fator de ajuste para processamento (FAP) para a fração CNF. Para o cálculo do NDT1x (Tabela 6), utilizou-se o FAP 0,94 proposto para silagem de milho normal.

Os teores de NDT1x (Tabela 6) calculados pela fórmula de Weiss et al. (1992) foram superiores, enquanto os calculados pela fórmula do NRC (2001), semelhantes ao valor descrito pelo NRC (2001) para silagem de milho normal $(68,8 \%)$ com MS entre 32 e $38 \%$. Silagens de milho contêm
Tabela 6 - Estimativas dos nutrientes digestíveis totais do material original e das silagens

Table 6 - Estimated TDN values of original material and silages

\begin{tabular}{lcccc}
\hline Item & $\begin{array}{c}\text { Material } \\
\text { original } \\
\text { Original material }\end{array}$ & \multicolumn{2}{c}{$\begin{array}{c}\text { Densidade de } \\
\text { compactação }\end{array}$} & $\mathrm{P}>$ \\
\cline { 3 - 4 } & & \multicolumn{2}{c}{ Packing density } & \\
\cline { 3 - 4 } & & $\begin{array}{c}\text { Média } \\
\text { Medium }\end{array}$ & $\begin{array}{c}\text { Alta } \\
\text { High }\end{array}$ & \\
\hline Weiss (\%) & 71,22 & 69,38 & 69,57 & 0,684 \\
NRC (\%) & 68,95 & 67,32 & 67,41 & 0,848
\end{tabular}

* Os dados do material original não fazem parte da análise estatística.

* Original material values are not analyzed statistically.

concentrações apreciáveis de amido e FDN e variações nas suas digestibilidades podem afetar seu valor energético (Weiss, 2005). Todavia, como neste experimento não ocorreu variação no teor de amido e houve pequena $(2,2 \%)$, mas significativa $(\mathrm{P}<0,05)$, variação no teor de $\mathrm{FDNcp}$, as equações somativas de Weiss et al. (1992) não apresentaram sensibilidade para detectar diferenças nos níveis de NDT1x.

Os valores de NDT $1 \mathrm{x}$ estimados por ambas as fórmulas (Tabela 6) foram superiores aos tabelados por Tedeschi et al. (2002) para silagens de milho produzidas no Brasil $(65,4 \%)$, estimadas pela equação de Weiss et al. (1992), e superiores também aos de NDT1x observado (60,2\%) e estimado (62,5\%) por Costa et al. (2005) pelas equações do NRC (2001). Cappelle et al. (2001), revisando os teores de NDT de silagem de milho na literatura brasileira, verificaram valores mínimos de $55,47 \%$ e máximo de $63,87 \%$.

\section{Conclusões}

A maior densidade de compactação permitiu melhor conservação dos glicídios solúveis, menor alteração dos carboidratos estruturais e menor proteólise na silagem, aspectos que favorecem a aceitabilidade e o consumo da silagem.

\section{Agradecimento}

Ao Conselho Nacional de Desenvolvimento Científico e Tecnológico, pelos recursos financeiros e pelas bolsas de estudo concedidos.

\section{Literatura Citada}

BACKES, A.A.; BONNECARRÈRE SANCHEZ, L.M.; GONÇALVES, M.B.F. et al. Determinação das frações da proteína e carboidratos de alguns alimentos conforme metodologia do CNCPS (Cornell Net Carbohydrate and Protein System). In: REUNIÃO ANUAL DA SOCIEDADE BRASILEIRA DE ZOOTECNIA, 37., 2000, Viçosa, MG. Anais... Viçosa, MG: Sociedade Brasileira de Zootecnia, 2000. (CD-ROM). 
BERCHIELLI, T.T.; SADER, A.P.O.; TONANI, F.L. et al. Avaliação da determinação da fibra em detergente neutro e da fibra em detergente ácido pelo sistema ANKOM. Revista Brasileira de Zootecnia, v.30, n.5, p.1572-1578, 2001

BOLSEN, K.K.; BOLSEN, R.E. The silage triangle and important practices in managing bunker, trench, and driver-over pile silos. In: SOUTHEAST DAIRY HERD MANAGEMENT CONFERENCE, 2004, Macon. Proceedings... Macon: 2004, p.1-7.

CABRAL, L.S.; VALADARES FILHO, S.C.; MALAFAIA, P.A.M. et al. Frações de carboidratos de alimentos volumosos e suas taxas de degradação estimadas pela técnica de produção de gases. Revista Brasileira de Zootecnia, v.29, n.6, p.2087-2098, 2000 (supl. 1).

CAMPOS, F.P.; BOSE, M.L.V.; BOIN, C. et al. Comparação do sistema de monitoramento computadorizado de digestão in vitro com os métodos in vivo e in situ. 2. Uso de resíduo da matéria seca de forragens. Revista Brasileira de Zootecnia, v.29, n.2, p.531-536, 2000.

CAMPOS, F.P.; SAMPAIO, A.A.M.; VIEIRA, P.F. et al. Digestibilidade in vitro/gás de volumosos exclusivos ou combinados avaliados pelo resíduo remanescente da digestão da matéria seca e produção de gás. Revista Brasileira de Zootecnia, v.30, n.5, p.1579-1589, 2001

CAPPELLE, E.R.; VALADARES FILHO, S.C.; SILVA, J.F.C. et al. Estimativas do valor energético a partir de características químicas e bromatológicas dos alimentos. Revista Brasileira de Zootecnia, v.30, n.6, p.1837-1856, 2001

COSTA, M.A.L.; VALADARES FILHO, S.C.; VALADARES, R.F.D. et al. Validação das equações do NRC (2001) para predição do valor energético de alimentos nas condições brasileiras. Revista Brasileira de Zootecnia, v.34, n.1, p.280-287, 2005.

DI MARCO, O.N.; AELLO, M.S.; NOMDEDEU, M. et al. Effect of maize crop maturity on silage chemical composition and digestibility (in vivo, in situ and in vitro). Animal Feed Science and Technology, v.99, p.37-43, 2002.

FERREIRA, J.J. Estágio de maturação ideal para ensilagem do milho e do sorgo. In: CRUZ, J.C.; PEREIRA FILHO, I.A.; RODRIGUES, J.A.S. et al. (Eds.) Produção e utilização de silagem de milho e sorgo. Sete Lagoas: Embrapa Milho e Sorgo, 2001. p.405-428.

HALL, M.B.; LEWIS, B.A.; van SOEST, P.J. et al. A simple method for estimation of neutral detergent-soluble fibre. Journal Science Food Agricultural, v.74, p.441-449, 1997.

HALL, M.B. Neutral detergent-soluble carbohydrates, Nutritional relevance and analysis: a laboratory manual. Gainesville: University of Florida, 2000. 42p. (Bulletin, 339).

JOBIM, C.C.; PEREIRA, J.R.A.; SANTOS, G.T. Sistemas de produção de leite com ênfase na utilização de volumosos conservados. In: REIS, R.A.; SIQUEIRA, G.R.; BERTIPAGLIA, L.M.A. (Eds.) Volumosos na produção de ruminantes. Jaboticabal: Funep; 2005. p.61-82.

JOHNSON, L.M.; HARRISON, J.H.; DAVIDSON, D. et al. Corn silage management: effects of maturity, inoculation, and mechanical processing on pack density and aerobic stability. Journal of Dairy Science, v.85, n.2, p.434-444, 2002.

JOHNSON, L.M.; HARRISON, J.H.; DAVIDSON, D. et al. Corn silage management: Effects of hybrid, chop length, and mechanical processing on digestion and energy content. Journal of Dairy Science, v.86, n.1, p.208-231, 2003.

LONDOÑO HERNÁNDEZ, F.I.; VALADARES FILHO, S.C.; PAULINO, M.F. et al. Avaliação da composição de vários alimentos e determinação da cinética ruminal da proteína, utilizando o método de produção de gás e amônia in vitro. Revista Brasileira de Zootecnia, v.31, n1, p.243-255, 2002.

MOREnO, J.A. Clima do Rio Grande do Sul. Porto Alegre: Secretaria da Agricultura, 1961. 41p.

MUCK, R.E. Effects of corn silage inoculants on aerobic stability. Transactions of the ASAE, v.47, p.1011-1016, 2004.

MUCK, R.E.; HOLMES, B.J. Factors affecting bunker silo densities. Applied Engineering in Agriculture, v.16, p.613-619, 2000.
MÜHLBACH, P.R.F. Produção de leite com vacas de alta produtividade. In: REUNIÃO ANUAL DA SOCIEDADE BRASILEIRA DE ZOOTECNIA, 40., 2003, Santa Maria. Anais... São Paulo: Sociedade Brasileira de Zootecnia, 2003. (CD-ROM).

MULLIGAN, F.J. QUIRKE, J.; RATH, M. et al. Intake, digestibility, milk production and kinetics of digestion and passage for diets based on maize or grass silage fed to late lactation dairy cows Livestock Production Science, v.74, p.113-124, 2002.

NATIONAL RESEARCH COUNCIL - NRC. Nutrient requirements of dairy cattle. 7.rev.ed. Washington D.C.: National Academy Press, 2001. 360p.

QIU, X.; EASTRIGDE, L.; WANG, Z. Effects of corn silage hybrid and dietary concentration of forage NDF on digestibility and performance by dairy cows. Journal of Dairy Science, v.86, n.11, p.3667-3674, 2003.

RANJIT, N.K.; KUNG JR., L. The effect of Lactobacillus buchneri, Lactobacillus plantarum, or a chemical preservative on the fermentation and aerobic stability of corn silage. Journal of Dairy Science, v.83, n.3, p.526-535, 2000.

SATTER, L.D.; REIS, R.B. Milk production under confinement conditions. Disponível em: <http:www.sbz.org.br/anais 1997/ simp/palest10.pdf $>$ Acesso em: 5/2/2005.

SAVOIE, P.; MUCK, R.E.; HOLMES, B.J. Laboratory assessment of bunker silo density part II: Whole-plant corn. Applied Engineering in Agriculture, v.20, p.165-171, 2004

SENGER, C.C.D.; MÜHLBACH, P.R.F.; BONNECARRÈRE SANCHEZ, L.M. et al. Composição e digestibilidade 'in vitro' de silagens de milho com distintos teores de umidade e níveis de compactação. Ciência Rural, v.35, n.6, p.1393-1399, 2005

SILVA, D.J.; QUEIROZ, A.C. Análise de alimentos: métodos químicos e biológicos. Viçosa, MG: Editora UFV, 2002. 235p.

SNIFFEN, C.J.; O'CONNOR, J.D.; van SOEST, P.J. et al. A net carbohydrate and protein system for evaluating cattle diets: II. Carbohydrate and protein availability. Journal Animal Science, v.70, n.11, p.3562-3577, 1992.

STATISTICAL PACKAGE FOR THE SOCIAL SCIENCES - SPSS User's guide: statistics. Version 11.5 Headquarters. Chicago: 2002. 1 CD.

STRECK, E.V.; KÄMPF, N.; DALMOLIN, R.S.D. et al. Solos do Rio Grande do Sul. Porto Alegre: EMATER/RS, UFRGS, 2002. 107p.

TEDESCHI, L.O.; FOX, D.G.; PELL, A.N. et al. Development and evaluation of tropical feed library for The Cornell Net Carbohydrate and Protein System model. Scientia Agricola v.59, n.1, p.1-18, 2002.

VALADARES FILHO, S.C.; ROCHA JR., V.R.; CAPPELLE, E.R. Tabelas brasileiras de composição de alimentos para bovinos CQBAL 2.0. Viçosa - MG: Universidade Federal de Viçosa, 2002. 297p.

VELHO, J.P.; MÜHLBACH, P.R.F.; GENRO, T.C.M. et al. Alterações bromatológicas nas silagens de milho submetidas a crescentes tempos de exposição ao ar após "desensilagem". Ciência Rural, v.36, n.3, p.916-923, 2006.

WALTER, M.; SILVA, L.P.; PERDOMO, D. Amido disponível e resistente em alimentos: adaptação do método da AOAC 996.11. Alimentos e Nutrição, v.16, p.39-43, 2005.

WEATHERBURN, M.W. Phenol-hypochlorite reaction for determination of ammonia. Analytical Chemistry, v.39, p.971-974, 1967.

WEISS, W.P. Adjusting net energy values of feeds fed to dairy cows. Disponível em: $<$ http://ruminantfeeds.org $>$ Acesso em: $13 / 4 / 2005$

WEISS, W.P.; CONRAD, H.R.; PIERRE, N.R. St. A theoreticallybased model for predicting total digestible nutrient values of forages and concentrates. Animal Feed Science and Technology, v.39, p.95-110, 1992

Recebido: 12/6/2006 Aprovado: 11/4/2007 